\title{
Successful Surgical Treatment of Metachronous Oligometastases from Non-B, Non-C Hepatocellular Carcinoma
}

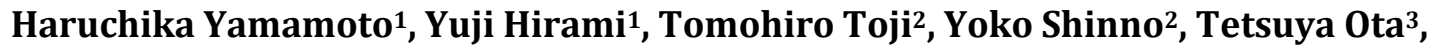 \\ Minoru Naito ${ }^{3}$, Akio Andou ${ }^{1}$ \\ ${ }^{1}$ Department of General Thoracic Surgery, National Hospital Organization Okayama Medical Center, Okayama, \\ Japan \\ ${ }^{2}$ Department of Pathology, National Hospital Organization Okayama Medical Center, Okayama, Japan \\ ${ }^{3}$ Department of General and Gastroenterological Surgery, National Hospital Organization Okayama Medical \\ Center, Okayama, Japan \\ Email: me17092@s.okadai.jp
}

Received 16 April 2016; accepted 28 May 2016; published 31 May 2016

Copyright (C) 2016 by authors and Scientific Research Publishing Inc.

This work is licensed under the Creative Commons Attribution International License (CC BY).

http://creativecommons.org/licenses/by/4.0/

(c) (i) Open Access

\section{Abstract}

Hepatocellular Carcinoma (HCC) rarely metastasizes to bone or mediastinum. In some patients, surgical treatment of oligometastatic lesions from colorectal cancer, breast cancer, or non-small cell lung cancer results in satisfactory survival. However, data concerning oligometastatic lesions from HCC are scarce. We report the case of a patient with long-term survival after resection of metachronous oligometastases of HCC. A 54-year-old woman underwent hepatic resection for non-B, non-C HCC. A solitary left tenth rib tumor was detected 20 months after initial surgery and was surgically resected. A solitary mediastinal tumor was detected 6 months after the second operation and the patient again underwent surgical resection. Histopathological examination of both lesions confirmed metastasis of HCC. The patient has had no further recurrence 7 years after initial surgery without chemotherapy or radiotherapy.

\section{Keywords}

Hepatocellular Carcinoma, Mediastinal Metastases, Rib Metastases, Oligometastases

\section{Introduction}

Recent reports have indicated that surgical treatment of oligometastatic lesions results in satisfactory survival,

How to cite this paper: Yamamoto, H., Hirami, Y., Toji, T., Shinno, Y., Ota, T., Naito, M. and Andou, A. (2016) Successful Surgical Treatment of Metachronous Oligometastases from Non-B, Non-C Hepatocellular Carcinoma. Open Journal of Thoracic Surgery, 6, 7-11. http://dx.doi.org/10.4236/ojts.2016.62002 
especially in patients with colorectal cancer, breast cancer, and non-small cell lung cancer [1]-[3]. However, data concerning oligometastases of Hepatocellular Carcinoma (HCC) are scarce. Extrahepatic metastases from HCC are usually not treated with locoregional therapies such as surgical resection, because uncontrolled intrahepatic lesions exist in many cases. HCC rarely metastasizes to bone or mediastinum, and metastases of HCC are generally associated with a poor prognosis. We report the case of a patient with long-term survival after resection of metachronous rib and mediastinal HCC metastases.

\section{Materials and Methods}

\section{Case Report}

A 54-year-old woman was admitted to our hospital for evaluation of a liver mass. Contrast-enhanced computed tomography (CT) showed a typical enhancing tumor $30 \mathrm{~mm}$ in diameter in segments III and IV. HCC was suspected. Laboratory testing revealed non-B, non-C (NBNC; negative for both hepatitis B antigen and hepatitis $C$ antibody) HCC with good preoperative liver function (Child-Pugh score A). Left lobe resection was performed. Histopathological diagnosis was nodular, moderately differentiated HCC, pathologic T2N0M0 stage II.

After hepatic resection, serum alpha-fetoprotein (AFP) fell to within the normal range (4.5 ng/dL 3 months after surgery compared with 10,927 ng/dL preoperatively). However, 1 year after initial surgery AFP had risen to $59 \mathrm{ng} / \mathrm{mL}$. Screening CT was performed every 3 months. AFP climbed to $282 \mathrm{ng} / \mathrm{mL}$ by 18 months after surgery. Twenty months after initial surgery, we detected a tumor $13 \mathrm{~mm}$ in diameter in the vicinity of the left tenth rib with destructive change (Figure 1(a)). At that time, AFP was 15,868 ng/mL. Bone scintigraphy showed positive uptake in a tumor of the left tenth rib, but 18F-Fluorodeoxyglucose Positron Emission Tomography (FDGPET) showed no tumor uptake. We suspected solitary metastases of HCC to the left tenth rib. Because no other metastases were identified, surgical resection was performed 22 months after initial surgery. The tumor of the left tenth rib with surrounding intercostal muscles was resected (Figure 1(b)). Histopathological examination confirmed metastases of HCC (Figure 1(c)).

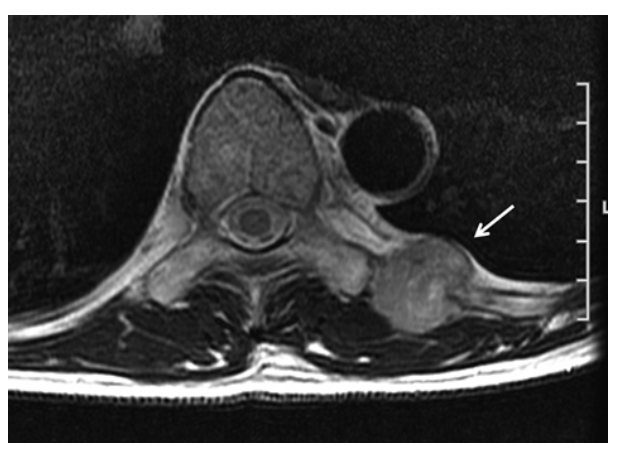

(a)

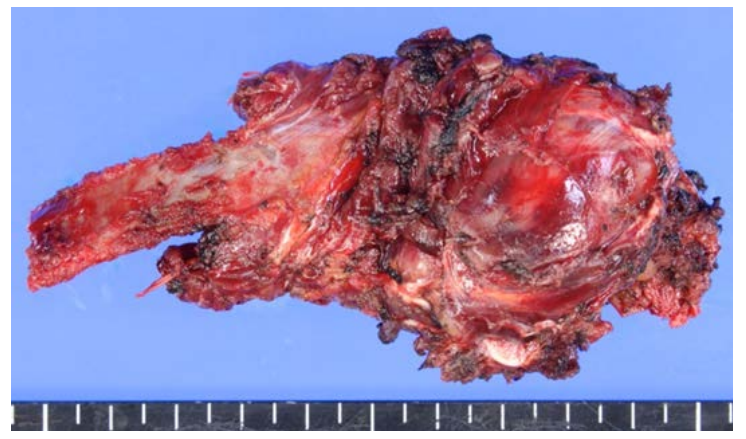

(b)

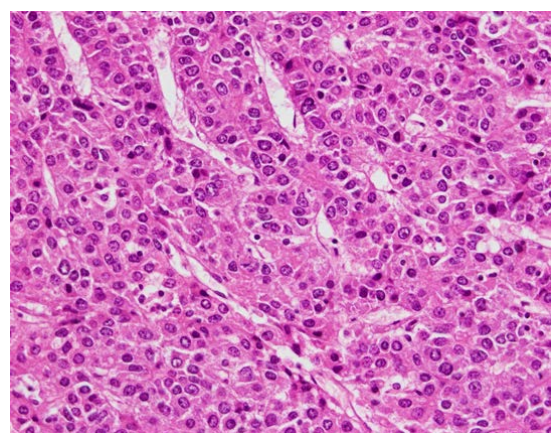

(c)

Figure 1. (a) T2-weighted magnetic resonance imaging shows a tumor $13 \mathrm{~mm}$ in diameter arising in the vicinity of the left tenth rib with destructive changes (arrow); (b) Tumor of left tenth rib was resected with surrounding intercostal muscles; (c) Histopathological examination confirmed HCC metastases to the left tenth rib (hematoxylin and eosin staining $\times 400$ ). 
After surgery, AFP decreased rapidly to $29 \mathrm{ng} / \mathrm{mL}$, but rose again 6 months after the second operation. This time, screening CT revealed a tumor on the left anterior mediastinum, $10 \mathrm{~mm}$ in diameter (Figure 2(a)). PETCT showed slight uptake by the mediastinal tumor (maximum standard uptake value, 2.19).

Solitary metastases to the mediastinum or lung was suspected. Video-assisted thoracic surgery was performed via a left-sided approach. A nodular tumor covered with parietal pleura was resected with mediastinal fat (possibly thymus) (Figure 2(b)). Histopathological examination confirmed mediastinal metastases of HCC (Figure 2(c)). Serum AFP decreased to within the normal range 3 months after the third operation.

There has been no other recurrence in the 7 years since initial surgery without chemotherapy or radiotherapy.

\section{Discussion}

We report a case of long-term survival after resection of NBNC-HCC with metachronous rib and mediastinal metastases.

HCC with extrahepatic metastases carries a poor prognosis, with a reported median survival of 8.1 months [4]. More than $85 \%$ of recurrences after surgical resection occur intrahepatically [5]. Bone metastases is seen in $6.3 \%$ of HCC patients. The most common site of bone metastases is the spine (39\%), followed by pelvis (19\%) and ribs (14\%) [6]. As many as $88.5 \%$ of patients with bone metastases from HCC die of liver failure resulting from intrahepatic tumor progression. Patients with uncontrolled intrahepatic tumor have a worse prognosis than those with well-controlled tumor. Liver function is an important factor in patients with HCC [7].

Solitary mediastinal metastases of HCC is rare, with only a few reported cases [8]-[10]. Survival over 24 months after resection of mediastinal metastases has been reported [10]; however, the efficacy of resection for mediastinal metastases remains unclear.

Sorafenib is the standard treatment for HCC patients with extrahepatic metastases [11]. Surgical resection of metastatic lesions is controversial [12]. Sakamoto et al. [13] reported that extrahepatic HCC metastases should be resected only if imaging studies indicate that the lesion is completely resectable and intrahepatic recurrence is absent or is controlled. HCC metastases are rarely treated with surgical resection because of coexisting intrahepatic lesions [12] [14].

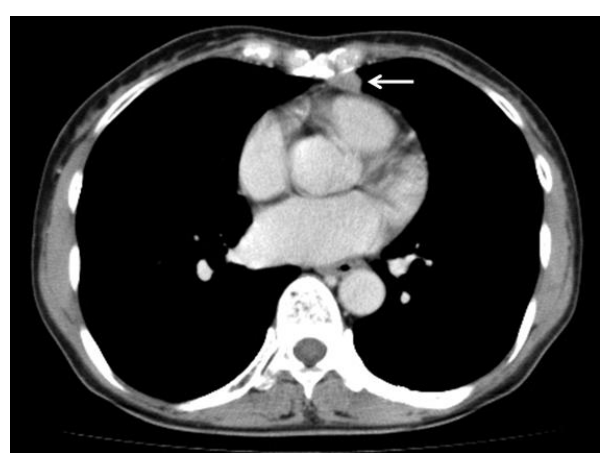

(a)

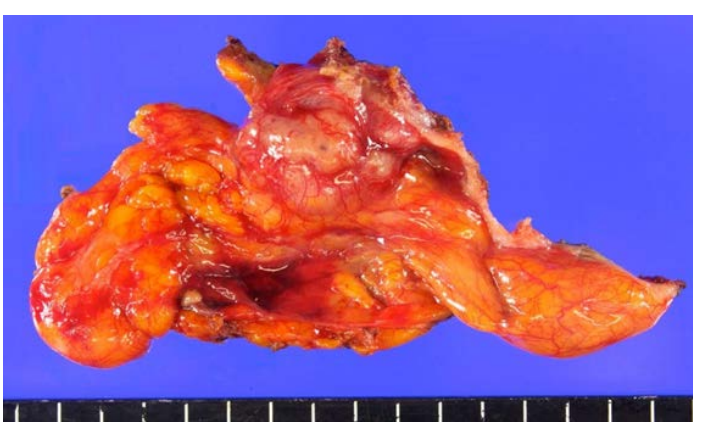

(b)

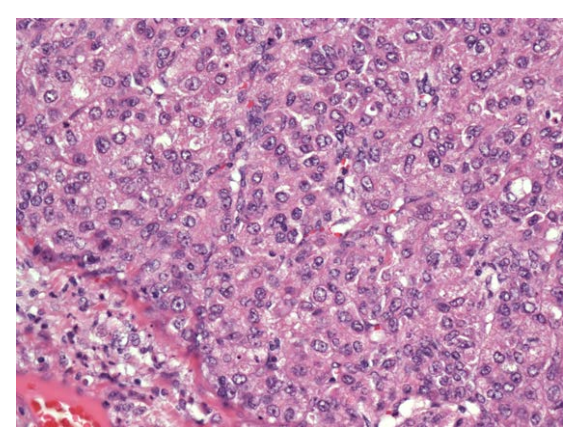

(c)

Figure 2. (a) Chest CT shows a round, well-defined tumor $10 \mathrm{~mm}$ in diameter located on the left anterior mediastinum (arrow); (b) Encapsulated tumor adjacent to thymus; (c) Histopathological examination confirmed HCC metastases to the mediastinum (hematoxylin and eosin staining $\times 400$ ). 
A recent study found that the incidence of NBNC-HCC has increased [15]. NBNC-HCC has a significantly better overall survival rate and a lower risk of HCC recurrence after hepatectomy than HBV-HCC and HCVHCC [16] [17]. NBNC-HCC recurrence is more likely to be extrahepatic rather than intrahepatic [16] [18]. These data suggest that surgical resection of extrahepatic metastases is more suitable for patients with NBNCHCC than for those with HBV-HCC or HCV-HCC.

\section{Conclusion}

In this case, complete resection of rib and mediastinal metastases of NBNC-HCC was possible. Surgical resection of oligometastases might be more suitable for NBNC-type HCC than for other types. Further studies in more patients are needed.

\section{References}

[1] Suzuki, H. and Yoshino, I. (2016) Approach for Oligometastasis in Non-Small Cell Lung Cancer. General Thoracic and Cardiovascular Surgery, 64, 192-196. http://dx.doi.org/10.1007/s11748-016-0630-7

[2] Tait, C.R., Waterworth, A., Loncaster, J., Horgan, K. and Dodwell, D. (2005) Theoligometastatic State in Breast Cancer: Hypothesis or Reality. Breast, 14, 87-93. http://dx.doi.org/10.1016/j.breast.2004.10.003

[3] Takeda, A., Sanuki, N. and Kunieda, E. (2014) Role of Stereotactic Body Radiotherapy for Oligometastasis from Colorectal Cancer. World Journal of Gastroenterology, 20, 4220-4229. http://dx.doi.org/10.3748/wjg.v20.i15.4220

[4] Uchino, K., Tateishi, R., Shiina, S., Kanda, M., Masuzaki, R., Kondo, Y., Goto, T., Omata, M., Yoshida, H. and Koike, K. (2011) Hepatocellular Carcinoma with Extrahepatic Metastasis: Clinical Features and Prognostic Factors. Cancer, 117, 4475-4483. http://dx.doi.org/10.1002/cncr.25960

[5] Taketomi, A., Toshima, T., Kitagawa, D., Motomura, T., Takeishi, K., Mano, Y., Kayashima, H., Sugimachi, K., Aishima, S., Yamashita, Y., Ikegami, T., Gion, T., Uchiyama, H., Soejima, Y., Maeda, T., Shirabe, K. and Maehara, Y. (2010) Predictors of Extrahepatic Recurrence after Curative Hepatectomy for Hepatocellular Carcinoma. Annals of Surgical Oncology, 17, 2740-2746. http://dx.doi.org/10.1245/s10434-010-1076-2

[6] Seo, H.J., Choi, Y.J., Kim, H.J., Jeong, Y.H., Cho, A., Lee, J.H., Yun, M., Choi, H.J., Lee, J.D. and Kang, W.J. (2011) Evaluation of Bone Metastasis from Hepatocellular Carcinoma Using (18)F-FDG PET/CT and (99m)Tc-HDP Bone Scintigraphy: Characteristics of Soft Tissue Formation. Nuclear Medicine and Molecular Imaging, 45, 203-211. http://dx.doi.org/10.1007/s13139-011-0099-3

[7] He, J., Zeng, Z.C., Tang, Z.Y., Fan, J., Zhou, J., Zeng, M.S., Wang, J.H., Sun, J., Chen, B., Yang, P. and Pan, B.S. (2009) Clinical Features and Prognostic Factors in Patients with Bone Metastases from Hepatocellular Carcinoma Receiving External Beam Radiotherapy. Cancer, 115, 2710-2720. http://dx.doi.org/10.1002/cncr.24300

[8] Suzumura, K., Hirano, T., Kuroda, N., Iimuro, Y., Okada, T., Hashimoto, M., Hasegawa, S. and Fujimoto, J. (2013) Solitary Mediastinal Metastasis of Hepatocellular Carcinoma Treated by Video-Assisted Thoracic Surgery: Report of a Case. General Thoracic and Cardiovascular Surgery, 61, 651-654. http://dx.doi.org/10.1007/s11748-012-0165-5

[9] Suga, A., Yamada, S., Takeichi, H., Masuda, D., Nakamura, Y. and Iwazaki, M. (2014) Recurrence in Regional Pulmonary Lymph Nodes after Surgery for Isolated Pulmonary Metastasis from Hepatocellular Carcinoma. General Thoracic and Cardiovascular Surgery, 64, 351-354. http://dx.doi.org/10.1007/s11748-014-0490-y

[10] Teramachi, M. and Nakagawa, M. (2011) A Case of Solitary Mediastinal Metastasis of Hepatocellular Carcinoma. Japanese Journal of Lung Cancer, 51, 736-741. (In Japanese) http://dx.doi.org/10.2482/haigan.51.736

[11] Llovet, J.M., Ricci, S., Mazzaferro, V., Hilgard, P., Gane, E., Blanc, J.F., de Oliveira, A.C., Santoro, A., Raoul, J.L., Forner, A., Schwartz, M., Porta, C., Zeuzem, S., Bolondi, L., Greten, T.F., Galle, P.R., Seitz, J.F., Borbath, I., Häussinger, D., Giannaris, T., Shan, M., Moscovici, M., Voliotis, D. and Bruix, J., SHARP Investigators Study Group (2008) Sorafenib in Advanced Hepatocellular Carcinoma. New England Journal of Medicine, 359, 378-390. http://dx.doi.org/10.1056/NEJMoa0708857

[12] Uka, K., Aikata, H., Takaki, S., Shirakawa, H., Jeong, S.C., Yamashina, K., Hiramatsu, A., Kodama, H., Takahashi, S. and Chayama, K. (2007) Clinical Features and Prognosis of Patients with Extrahepatic Metastases from Hepatocellular Carcinoma. World Journal of Gastroenterology, 13, 414-420. http://dx.doi.org/10.3748/wjg.v13.i3.414

[13] Sakamoto, K., Nakashima, K., Migo, S., Hasuda, K. and Anai, H. (2002) A Study of Treatment for Extrahepatic Metastasis after Surgical Treatment of Hepatocellular Carcinoma. Japanese Journal of Gastroenterological Surgery, 35, 116-119. (In Japanese) http://dx.doi.org/10.5833/jjgs.35.116

[14] Katyal, S., Oliver 3rd, J.H., Peterson, M.S., Ferris, J.V., Carr, B.S. and Baron, R.L. (2000) Extrahepatic Metastases of Hepatocellular Carcinoma. Radiology, 216, 698-703. http://dx.doi.org/10.1148/radiology.216.3.r00se24698

[15] Nishikawa, H. and Osaki, Y. (2013) Non-B, Non-C Hepatocellular Carcinoma (Review). International Journal of On- 
cology, 43, 1333-1342. http://dx.doi.org/10.3892/ijo.2013.2061

[16] Utsunomiya, T., Shimada, M., Kudo, M., Ichida, T., Matsui, O., Izumi, N., Matsuyama, Y., Sakamoto, M., Nakashima, O., Ku, Y., Takayama, T. and Kokudo, N., Liver Cancer Study Group of Japan (2015) A Comparison of the Surgical Outcomes among Patients with HBV-Positive, HCV-Positive, and Non-B Non-C Hepatocellular Carcinoma: A Nationwide Study of 11,950 Patients. Annals of Surgery, 261, 513-520. http://dx.doi.org/10.1097/SLA.0000000000000821

[17] Hayashi, T., Hirai, S. and Shimatani, A. (2010) Clinicopathological Characteristics of Surgically Treated Patients with Non-B Non-C Type Hepatocellular Carcinoma. Kanzo, 51, 697-705. (In Japanese) http://dx.doi.org/10.2957/kanzo.51.697

[18] Okamura, Y. (2013) Clinicopathological Characteristics of Increasing Non-B and Non-C Hepatocellular CarcinomaFrom a Viewpoint of a Surgeon. Liver Cancer, 19, 35-40. (In Japanese) 